\title{
The Exploring and Improvement of Teaching Method about the Course "The Design Principle of Concrete Structure"
}

\author{
Xia Shan* \\ School of Civil Engineering \\ Anhui Jianzhu University \\ Hefei, Anhui, China \\ *81490271@qq.com
}

\author{
Ding Ke-wei \\ School of Civil Engineering \\ Anhui Jianzhu University \\ Hefei, Anhui, China \\ dingkw@ahjzu.edu.cn
}

\author{
Cui Jian-hua \\ School of Civil Engineering \\ Anhui Jianzhu University \\ Hefei, Anhui, China
}

\begin{abstract}
This article analyzes the course characteristic of "The Design Principle of Concrete Structure" under the background of "Excellent Engineering Education and Training Program". Contraption some common problems, the research group propose some relevant improvement suggestions to the teaching of "The Design Principle of Concrete Structure" from the viewpoint of teaching measures and teaching means. Expecting the analysis to be effective in civil engineering education.
\end{abstract}

Keywords-The Design Principle of Concrete Structure; teaching methods; teaching means; improving measures

\section{INTRODUCTION}

The "Excellent engineering Education and Training program" is a higher education major reform plan for thoroughly implementing the Party's 17th National congress of the People's republic of China on Chinese Characteristic New Industrialization, Building an Innovative Country and Building a Powerful Human Resources Country and other strategic plans, and completely implementing the "Outline of the National Medium and Long term Education Reform and Development Plan (2010-2020)". The "Excellent engineering Education and Training program" has a significant demonstration and guidance role for higher education in cultivating talents for social needs, adjusting the structure and improve the quality of personnel training, promoting education and teaching reform and enhancing the employability of graduates[1].

"The Design Principle of Concrete Structure" course, whose teaching achievement plays a role which cannot be neglected for the realization of goal of excellent engineer training, is the core course of civil engineering. Therefore, finding and adapting appropriate methods of the educational idea implement of "Excellent Program" in this course, reasonable reconstruction of the knowledge system, the improvement of the teaching content and the innovation of the teaching method has become the most urgent problems which should be solved in the teaching reform of civil engineering profession. The research group of "The Design Principle of Concrete Structure", which has a number of experienced teachers, concentrating on the characteristics of the course, brainstorming, integrating ideas, analyzing the existing problems and reform ideas, and exploring the suitable teaching methods for the current situation to resolve problems which are enumerated above.

\section{The Course Characteristics of "The Design Principle OF CONCRETE STRUCTURE"}

Concrete structure, which is the most widely applied structure type in the civil engineering realm in the worldwide range, has become the most important specialized subject in civil engineering field since it emerged 170 years ago . The importance of concrete structure is tangibly as the concrete structure design specifications are applied as the symbol of the level of structural construction in the national construction standards of all the countries around the world. Meanwhile, with the development of engineering needs and forms, the content and knowledge of concrete structure are updated in real-time. What is more important is that, concrete structure methods contain the basic philosophy in problems solving of civil engineering, it can be said that, without comprehending the knowledge and application of concrete structure, students cannot become a qualified civil engineering. "The Design Principle of Concrete Structure" course plays the role of junction in the professional curriculum establishing, linking both the foundation courses of the university (advanced mathematics, linear algebra, etc.) and professional foundation course ( mainly The Three Mechanics) together, and opening the door of civil major for students, at the same time, laying a foundation for the subsequent professional foundation courses (high-rise structure, structural seismic, steel structure, etc.) and 
methodology. The main feathers of learning this course are followed:

\section{A. The special materials of concrete}

Another writing of concrete in Chinese is "tong", which means artificial stone. In practice, concrete is a kind of brittle mixture material, which has solid phase, liquid phase, and gas phase three phase internal at the same time. Meantime, in applications, concrete is combined with stiff steel or flexible steel, which contributes to its extreme complex structural performance, hence there are many complex force stages, such as linear stage and non-linear stage, when the concrete is under stress. Moreover, it is difficult to utilize a certain theory to analyze its structural performance precisely under different loads (tension, compression, bending, twist and etc.) and time parameters (short-term, long-term, quasi-permanent and etc.). Therefore, it is difficult for students to understand and grasp the essence of concrete structure in a short period, as the course has been a small half, the basis of concrete theory -- the bending stage-- has been introduced, students can only have a little experience, and inevitable out of touch from the course.

\section{B. The concrete theory - "hazy feeling" in course learning}

Prior to concrete theory learning, 14 to 15 studying experience of students results in their thinking characteristics and problem-solving tendency of rigorous logical reasoning, closed theoretical knowledge, and ideal precondition. However, due to the material and structural particularity from point $A$, the uncertainty of the structure increases[2]. This uncertainty causes concrete theory is difficult to form a mature closed theoretical system, normally, the derivation of semiempirical semi-theoretical formula needs the assistant of the empirical coefficient and various assumptions. In the concrete theory, problems normally have several solutions, such as the component of structure is not the bigger the better, the steel is not the more the better, it is difficult to complete the optimal analysis instantly. For this reason, the determination of program is often accompanied by a number of disorganized construction measures. Students who are unfamiliar with civil major are usually confused by the "hazy feeling", which make them lose passion and motivation.

\section{The harsh requirement in learning}

Concrete structure is a very practical course, as previous description, most of semi-empirical semi-theoretical formula and methods derived from repeated trivial experimental analysis and accumulated from thousands of projects. If students only learn the foundation theory without practice in teaching process, they cannot employ theories into practical applications. Therefore, except for feathers of complexity of material and structure, the learning process is more complex compared with other courses. In addition to class room teaching, a variety of experiments, internships and other practice are interspersed into the teaching block. Nevertheless, in most universities in China, because of the large number of students, teaching resources are in lacking, in most of universities and institutions in China, theoretical lessons are taught in a large class, practice is in a serious lacking. Structural tests becoming classroom multimedia display, rather than practical preparation, full operation and data analysis. Internship period is compressed from stationed in construction site for days to day-trip. As a result, Training objectives of "Excellent program" are difficult to achieve, the quality of graduates cannot be guaranteed.

\section{The IMPRovement OF TEACHING METHOd OF " THE DeSIGN PRINCIPLE OF CONCRETE STRUCTURE" COURSE}

According to the characteristics of "The Design Principle of Concrete Structure" course and some common problems in present course teaching, the research group has conducted effective research and induced some relevant improvement measures.

\section{A. Combining both multimedia and blackboard writing in practical teaching}

Under the framework of the "Excellent program", teaching tasks of concrete are very practical, but heavy as well, thus verifying all problems in practical situation is almost impossible. To reaching as much as possible in limited class time, multimedia and advanced software, for example BIM, are needed to be introduced. This requires large number of pictures and videos data and responsible teacher who can carefully design the teaching process to save time, making the classroom teaching becomes efficient and effective.

What should be pointed out is, this course covers a large number of theoretical formula derivations, if over-reliance on multimedia, there could be teaching progress too fast, students cannot understand the key content in detail and other problems. To avoid these circumstances, teachers should balance the poise between blackboard writing and multimedia, conduct students to demonstrate, the traditional and helpful method, at key knowledge points, and formula derivations.

\section{B. Reinforcing the basis, promoting hand counting, then flexible applying}

"Know It" and "Know Why." In modern undergraduate teaching process, many teachers spend profuse energy on teaching "Know It", they need balance adequate energy on "Know Why". However, concrete subject is the combination of experience and theory, results of theoretical derivation id the core and skeleton of formula, then supplemented with the empirical coefficient. Therefore, understanding the theories is far more important than remembering and sticking to them. Actually, for most undergraduates, classroom teaching is only opportunity to conduct a thorough theoretical study in concrete theory learning. Thence teachers should take the trouble, revealing model utilizations, basic assumptions, mathematical deduction and the determination of value of empirical coefficient to students, so that they can understand and grasp the theory, have less "hazy feeling", and more selfconfidence.

\section{Conjunction the forefront of the development of subject, advancing with the time}

As the appearance of new materials and expansion of structural utilization demanding, the accumulation of scientific research and engineering practice promotes the swift 
development of concrete structure theory, for example, due to large-scale rapid development, the amount of detection and reinforcement of structure increase. At this time, cultivation of students' sense of responsibility for engineering, solid learning and adhering of professional ethics are in very high priority. In addition, introduction of reasons for problems and solutions are also necessarily. Moreover, as the implementation of the new specification, teachers must introduce the new standard of the revised office, bring the latest industry information to students; FRP materials and a variety of steel reinforced concrete are in wide range application in structure in the modern world, it is necessary to cast a number of professional face to students, to develop their engineering awareness, and stimulate their interests.

\section{Strengthening practices, conjugating knowledge}

The characteristic of concrete structure theory is theory is inseparable linked with practice; meanwhile, the main purpose of higher education is to nurture talents and improve the comprehensive quality and ability of students, especially the ability of problem analyzing and resolving. Therefore, in the class teaching process of "The Design Principle of Concrete Structure", it should be paid additional attention to strengthen the cultivation of practical ability of students.

As for students, it is necessary to attempt to practice initiatively, visit the concrete structure which is under construction, such as the template erections, steel bandings, and structural reinforcement positions before the class. When they have some sense of sensibility, it is easier to correspond theories to memories in practice in class learning, then they can not only have a sense of accomplishment, but also a broaden horizon.

Students will generally be arranged one to two weeks of curriculum design after theory learning in classroom. This is a important process that students will understand theories deeply, conjugate knowledge points and learn methods of applications. Thence, the curriculum design must not be questions solving. In the period, plagiarism should be absolutely eliminated and hand-counting should be promoted, students should apply legislation in map drawing. In programs selection, different programs should be chosen by students which are variables controlled that can be compared, such as with consistent beam board size, but different column sizes or different loads, this can reflect the importance of program design. And after designing, students should compare their programs, discussing and then establishing emotional structure concept design.

\section{E. Inspiring, contacting reality and activating atmosphere in class}

As mentioned before, students who have been trained in intensive science are unfamiliar to the concrete structure at the beginning. Naturally, teachers should use appropriate teaching methods to provide a lively and vivid classroom, bring students into the professional state as soon as possible with easily understandable and life closing examples.

When author is doing the explanation of the concrete structure for the durability of the explanation, encountered an article "which countries had given up Chinese characters?", which said: "As the phonetic characters Korean characters are not easy to appear ambiguous, and even leads to jokes. There is an important high-speed rail in South Korea, the concrete sleepers need waterproof foam filter, but the construction side has used a water-absorbing material, resulting in 155,000 root pillows crack. Finally, the engineering team found that the reason is wrong to understand the wrong description of the text, the "waterproof" wrong as "water-absorbing".

This kind of application active classroom atmosphere and clearly let students recognize the durability of concrete and water. Along with the students laughing and knowing and national priding, knowledge is grasped.

\section{CONCLUSIONS}

In the practice of course teaching of concrete structure, it is necessary to closely focus on the objective of "Excellent program", establish advanced training programs and good teaching conditions[3], actively explore new teaching methods to improve teaching effectiveness, cultivate students' ability of thinking and analyzing. In the future, teachers should still work hard to explore more effective teaching methods; constantly meet the new situation of personnel training demands.

\section{ACKNOWLEDGMENT}

Foundation item: "Research on the reform and practice of Civil Engineering Specialty in Anhui province" 2013 revitalization plan for major teaching reform research projects in Anhui Province(2013zdjy193)

\section{REFERENCES}

[1] Ministry of Education. The ministry of education several opinions on the implementation of education to cultivate outstanding engineers plan(R).2011.

[2] Xu Youlin. "Give a man a fish, and you'll feed him for a day. Teach to fish you will feed him for a lifetime "[J]Journal of Southeast University(philosophy and social science edition2012,14(s):7-10

[3] Peng Yaping,Xie Qun. "Based on the concrete structure course teaching reform to cultivate excellent engineer[J].Journal of Southeast University(philosophy and social science edition)", 2012,14(s):144-146 